DOI: https://doi.org/10.47405/aswj.v5i2.139

\begin{tabular}{|c|}
\hline $\begin{array}{c}\text { Asian SOCIAL WORK } \\
\text { JURRAL } \\
\text { (ASW) }\end{array}$ \\
Volume 5, Issue 2, July 2020 \\
\hline \\
\hline
\end{tabular}

\title{
Dealing with Juvenile Delinquency: Integrated Social Work Approach
}

\author{
Paramjit Singh Jamir Singh ${ }^{1}$, Azlinda Azman ${ }^{1}$ \\ ${ }^{1}$ Social Work Programme, School of Social Sciences, Universiti Sains Malaysia (USM), Malaysia
}

Correspondence: Azlinda Azman (azlindaa@usm.my)

\begin{abstract}
Juvenile delinquency poses a constant social challenge to the public. Juvenile delinquency can be defined as a repeated social disorder among children or adolescents. In this regard, human behaviour and the environment are linked to each other. Hence, the distortion of one aspect will definitely affect the latter. This article presents a comprehensive intervention where the integrated social work approach was applied to deal with juvenile delinquency. The integrated social work approach has become a framework for social work as it focuses on both the individuals and the environment. This framework has been applied to reduce the gap between individuals and their environments, and it is very important for social work intervention. Since the nature of this framework encompasses several different professions, it has become beneficial for social workers to deliver a multi-context intervention and assessment that is based on the preventive, rehabilitative, and development perspectives, especially in the case of juvenile delinquency. The implementation of an integrated social work framework in the line of a social worker's profession could bring advantages in terms of pinpointing the cause of the problems. Finally, social workers will be able to address juvenile delinquency problems through appropriate techniques.
\end{abstract}

Keywords: assessment, integrated social work approach, juvenile delinquency, social functioning, social work intervention

\section{Introduction}

Social work, as we today, started since the early days of mankind where the needs of one person was fulfilled by another based on concern for the latter. Fulfilling needs is necessary in order for something to function well in the society. On the other hand, concern refers to the interest or regard for the wellbeing of one's self or others (Coady \& Lehmann, 2016). Needs, especially those related to human development appear in various forms, such as physical, social, emotional, cognitive and spiritual needs. Social work, regardless of being initiated by the government or the private sector is significant in delivering social services to needy individuals. Levenson (2017) expressed that social work addresses problems in psychosocial functioning, helping individuals to achieve their life goals and creating a fair and just society.

Social work also helps an individual or a community to trigger changes in the social aspect. The definition of 'change' itself is quite diverse, complicated and often regarded as risky. To understand this, a social worker requires a detail approach which consists of combination of knowledge, values, skills, imagination, comprehension and creativity. Therefore, the change of mind set from 'Knowledge' to 'Knowledge as product' is necessary. Excellent social workers must be able to help meet their clients' social obligations. Moreover, they need to address and overcome long term 
DOI: https://doi.org/10.47405/aswj.v5i2.139

problems in communities, organizational structures, social policy, and translate social policies into beneficial programmes and services (Gherardi \& Whittlesey-Jerome, 2018).

\section{Integrated Social Work Practice}

Historically, the integrated social work practice is a framework for social work focusing on both the individual and the environment. The purpose of the framework is to reduce the gap between individuals and their environments. Integrated practices provides a useful framework, which allows social workers to take proactive measures to define social problems and mobilise resources to resolve these issues (Canda, Furman, \& Canda, 2019). In this light, social workers must be able to describe human behaviour and social environment, identify how the changes occurs and formulate intervention to enhance social work intervention.

By collaborating with different professionals, social workers will be able to practice multi-context intervention and assessment of their clients, specifically from a preventive, rehabilitative and development perspective. As social workers may lack the competency to single-handedly solve their clients' problems, profession-integration serves as a medium to gather professional knowledge from different fields to address and overcome certain issues. This medium enables social workers to deliver services holistically and examine clients' requirement in a larger context. For instance, in a school environment, school social workers are able to provide in-depth assessment based on information obtained from teachers regarding student's behaviour problem in the classroom. Moreover, teachers can play active role in assisting social workers through monitoring the changes in the client's behaviour in the classroom (Gherardi \& Whittlesey-Jerome, 2018).

Undoubtedly, the integrated approach does bring a lot of benefit to the clients, such as access to various a services as well as flexible and economical use of resources available. Hence, clients are better treated as the different service units work together. In addition, this approach also implements holistic and personalised approach to all groups in the society, without any exception (Comprehensive coverage). Based on this approach, agencies will focus first on the needs of their clients and society, which will lead to a better and comprehensive care. Social worker is also able to utilise different content and level approach in order to meet the clients' needs. Likewise, the integrated social work approach can act as a response towards the uncertain needs of clients and society (Ife, 2019).

The integrated approach also focuses on clients' convenience. Since an integrated centre provides various services in one location, clients will be able to find resources faster without the need to travel from other place to another. As profession-integration improves the communication and co-operation among different professionals, social workers are able to recognise these professions and the related resources much faster. Different professions will have better support through communication and discussion between professionals. Such communication has proved to be useful in providing services or designing an intervention plan. In the context of a school, the school social workers support teachers by handling students' emotional problem, which, subsequently, help teachers to teach the class effectively (Gherardi \& Whittlesey-Jerome, 2018).

Since there are several factors that lead to these issue, 'Orienting theories' could provide a possible explanation on juvenile delinquency. These factors comprise of different levels of systems from individual to the national context, such as personality, organization functioning and political influences. This theory points social workers towards the importance to understand problems from various discipline, for instance biology, cultural anthropology, economics, psychology and sociology to achieve the goal (Gehlert \& Ward, 2019).

'Practice perspective' is a method that can be used to observe and identify important information in a practice situation. This perspective acts as a guide for social workers as it helps them to adjust and adapt their thoughts in addressing problems. Considering the numbers of frameworks existed out there, it might assist social workers to choose solutions that fit the problems that they are facing. Moreover, since social interactions are ever changing, this practice theory is able to clarify specific 
behaviours based on situations. Zastrow (2016) asserted that this practice model, which implemented during intervention activities, consists of combination of concepts and principles.

The integrated approach is critical in the field of social work as it combines a range of approaches and methods, as well as providing a guidance for social workers in observing, describing and explaining different behaviours observed. Based on the observations made, social workers will be able to link, predict and intervene changes to ensure a more effective implementation. In terms of participation, social workers' actions are as comprehensive as the other professions. Professionals bring a plethora of expertise, which could guide the intervention process. The last few decades showed that individuals have become inconsiderate towards professionals, which forced social workers to be more open and democratic social workers. In other words, social relations is recognised as one of the stakeholders and it can be incorporated into the practice of help. This kind of help is normally offered to the societies where the individuals are detached and disconnected (Gherardi \& Whittlesey-Jerome, 2018).

Social justice is another essential aspect of social work. A strong leadership can be viewed as one of the outcomes of the anti-discriminatory practices in social work. Social justice also focuses on the social model outcomes that affect $\mathrm{t}$ individual, family, community and welfare rights. Hence, individuals that suffer from social injustices will receive help in form of specific services individually, and at the same time, help in social responses, generally. Social just cannot be neglected and separated from social work. This is because it affects the clients and the social services being offered by the social workers. Thus, it could be argued that solely focusing on the clients' needs and social workers' services are not adequate in this situation. In this regard, social workers would normally deal with individuals with severe behaviour disorder based showing the possible the consequences of their actions to the victims and their families (Childress, Gioia, \& Campbell 2018).

\section{A Review on Juvenile Delinquency}

Juvenile delinquency is an endless social problem (Heynen et. al, 2018). It can be defined as an abnormal social behaviour disorder prevalent in children or adolescents who repeatedly commit crime. Ogundele (2018) explained that juvenile delinquents usually demonstrate mental disorders and abnormal behaviours, which lead to post-traumatic stress disorder or bipolar disorder. Consequently, partial conduct disorder may emerge due to their delinquent behaviours. Experts have come up with numerous theories to explain the cause of these problems, which have a significant effect towards the development of precautionary measures against delinquency

The 'Social Learning Theory' by Bandura indicates that humans, including children, learn by copying things that they observe around them (Heves, 2017). In this regard, children will imitate t delinquent behaviours, such as abusing drugs and violence, if their parents show their parent performing such behaviour, without realising the behaviour imitated is wrong. This problem further escalates due to the weakness of family structure in this era, subsequently, more children would experience unpleasant situation at an early age which has been linked to criminal behaviour when they are older. Reports have shown that children raised by a single parent have higher tendencies for engaging in crimes as they tend to lack parental love, care and guidance. This could be caused by the lack of attention given by some to the children as they need to take on the role of the sole breadwinner and parent to their children. Thus, it could be assumed that the weakness of the family structure largely contributes to higher number of juvenile delinquency cases in recent years.

The 'Social Strain Theory' expressed that children turn to criminal behaviour when they are not able to reach their goals through appropriate means (Agnew, 2019). As children born into poor families lack economic means to achieve higher social status, wealth and access to employment, subsequently, children from lower socio-economic status tend to resort to illegal means to achieve the same things. However, despite this logical explanation, this theory cannot be accepted completely because juvenile crimes are not only restricted to children from the poor community, but also children from wealthy backgrounds. In addition, this theory does not clarify the causes of violence and abuse committed by young children and teenagers. 
On the other hand, Von Stumm (2017) found out that children with low intelligence are more likely to underperform at schools. In this regard, underperforming children have higher tendency for committing a criminal offence die to low educational attainment, a low attachment to school, and low educational aspiration. Hawkins and Weis (2017) also affirmed that children who perform poorly at school are more likely to commit delinquent behaviours, such as playing truant.

Peers also play a role in the delinquent behaviour among children. As children grow up and enter their teenage years, they spend more time with their friends rather than their family. In this situation, if the children are not provided with proper education, peer group may expose them to delinquent behaviour. Studies also found that watching violent shows and films at a regular basis may contribute to delinquent behaviour (Hawkins \& Weis, 2017).

Delinquency Prevention is a general term for all efforts targeted on preventing school children from involving themselves in criminal or antisocial activity. However, delinquency prevention should not only cover the factors that contribute to delinquency, but also to the extent to which the etiological factors interact in the process of social development (Sullivan, \& Hirschfield 2017).

\section{Juvenile Delinquency in Social Work Context}

It is important for social workers dealing with juvenile delinquency to view this problem as a whole. Ideas generated by social workers are beneficial to assist and improve the wellbeing of those involved in juvenile delinquency behaviour. This situation is actually conforming to the fundamental goals of social work as a profession that includes services that focus on addressing problem, improve social functioning, and enhance the capacity and quality of life of individuals, groups or communities. The philosophy of social work revolves on the idea of belief and attitude of the aspirations, goals, values and norms, practices and ethical principles embodied in any profession. Social work profession is embedded with this philosophy, which provides the rationale and objectives for the service. This philosophy consists of two elements, moral, which focuses on moral values as well as the social element which covers the social norms (Sandu \& Frunza, 2018).

The value of social work relates to the orientation, process and situation occurring in the society. Hence, a social workers need to take the appropriate action to meet human development needs. Their values comprise of the concept of human, impact to the individuals and value (Barsky, 2019).

Fundamentally, social work is based on the recognition of other people's worth, dignity and rights (Sandu \& Frunza, 2018). Social workers can promote and defend every physical or mental aspect of in many ways. First, social workers should respect and advocate people's rights so they can make their own decision without impacting others illegally. Second, social workers should promote the services they provide to prospective clients. By right, these services should empower individual clients, especially when making decisions on important events in their lives. Third, social workers need to treat each client as a whole and consider every stakeholder and events that revolve around him/her. Fourth, social workers should focus on identifying and developing strengths all across entities including the individual client as well as his/her family and community and the society as a whole.

Integrated social work approach demands social workers to incorporate their skills, knowledge and values into the social work profession. Whenever help is required, social workers need to be able to fuse all of their available knowledge, values and skills in a creative and appropriate manner. It is also vital that these elements are used together in any given time and environment to ensure the provision of comprehensive and holistic services for those in need (Coady \& Lehmann, 2016).

\section{Components of Effective Social Work Intervention}

\section{Professionally Accountable Practice}


Competent social workers, especially those who are involved with juvenile delinquency must hold on to professionally accountable practice. In incorporating such practices in the practitioner/social workers' services or interventions, all their actions should be based on the following aspects:

i. Conscious - social worker is always aware of what he/she is doing,

ii. Planned - the social workers know what to do beforehand and has conceived a plan on how to achieve it

iii. Directed - the social worker, client, agency and society work towards clear outcome goal/purpose,

iv. Informed knowledge - the social worker uses professional knowledge in order to have a complete understanding, considering the client and the situational context before executing the plan, and

v. Accountability - the social worker is always able express his practice in public and provide the reasons of the practice method taken.

\section{Assessment on Psychosocial and the Social System Model}

A competent social workers will typically run a psychosocial assessment on the client to develop a deeper understanding of their client's problem. In this light, a social worker will gather information from the different aspects of the client's life, whether individual or the environmental aspects. According to Larkin (2018), social workers formulate their own opinion by identifying which of client's system(s) that requires the most attention and worth for intervention. This system is known as to the main system. For instance, a social worker handling a young boy who showed problematic behaviour at the school. By utilizing the assessment process, social worker could identify the cause of the problem, which could possibly due to different factors such as learning disability, family problem, overcrowded environment at school and others.

Based on the information gathered, a social worker will be able to strategise the intervention, by emphasising the system that requires immediate attention and most likely grant a positive effect to the overall situation. The social systems model embodies knowledge from various fields such as biology, psychology, and sociology easily. As the individual and the environment are coupled together, they can be considered as a single system because they mutually depend on each other. Thus, the whole ecosystem will be affected when there is any disturbance found in any part of the system (Aktipis et al., 2018).

Since there are a lot of systems involved, therefore, social workers need to look on the systems as a whole in order to understand juvenile delinquency. The general systems theory is fundamental to many social workers because it allows the social workers to relate their experiences with the theory. The theory lets the social workers to focus and analyse the interaction of the person collectively, including interactions between the person and other systems, larger systems and smaller systems (Gallant \& Thyer, 2017). Gherardi and Whittlesey-Jerome (2018) indicated that social problems are pervasive across all levels of the system. In the meantime, any interactions across various system levels may create, alleviate or worsen the social problems.

The implementation of integrated social work approach could assist social workers to understand juvenile delinquency as a whole. Concurrently, it may help social workers to devise a good intervention for this problem. From the social workers' point of view, the client must be seen as a person-in-environment. Throughout the history, social work profession focuses on person-inenvironment perspective in any helping process (Greene, 2017). This perspective emphasizes the interconnection of a person and its surrounding such as families, social networks, and society at large. A competent social worker must be able to a comprehensive framework, which incorporates different social work theories, methods, skills, values and knowledge to tackle the problem.

Micro systems, could comprise of individuals, families and groups who interact within themselves as well as with the bigger mezzo systems, such as communities, neighbourhood and organizations. 
DOI: https://doi.org/10.47405/aswj.v5i2.139

Meanwhile, mezzo systems interact with larger macro systems and social institutions including policies, the legal system, the economic system, the media and the social welfare systems, which are possibly existed within the social problem. Hence, intervention needs to be targeted towards all three levels to address juvenile delinquency.

\section{Synchronization of Micro-Mezzo-Macro Intervention Focus}

Efficient social workers will involve all three micro, mezzo and macro levels throughout the helping process. Zastrow (2016) expressed that social workers should be able to form relationships with clients, define issues, identify strengths and problems, collect and evaluate information. Based on the information gathered, potential interventions and plans supported by clear goals and objectives can be created. After that, they can implement, monitor, or terminate the interventions accordingly. In the end, assessment and follow up can be conducted to measure the effectiveness of the interventions. Essentially, social workers must consider their client as a person-in-environment in favour of understanding their client situation and perhaps bring a change to the client's behaviour and environment.

An effectiveness intervention process is possible through the implementation of diverse practice theories and approaches, and the selection of accurate models based on the client's needs and resources (Gherardi \& Whittlesey-Jerome, 2018). In addition, social workers who are working on juvenile delinquency must consider theories related to this phenomenon. Researchers such as Alston and Bowles (2019) agree that social workers need to apply different theories into their professional practices. In this regard, the social control theory (Hirschi, 2017) provides a useful framework, which allows social workers to view juvenile delinquency at the micro level. This theory assumes that delinquency behaviour can be restrained through the bond between the individual and society. The bond, which was conceptualized by Hirschi (2017), comprises of four parts. First, the attachment an individual has towards others in a psychological and emotional way. Second, attachment creates commitment, which often makes the individual has second thoughts on engaging on a delinquent behaviour. Third, when the individual spends more time on conventional activities, he will have little opportunities to be involved in delinquency. Fourth, having a solid belief on conventional values decreases the chance of delinquent behaviour. Nevertheless, children need to be controlled or supervised directly, and sometimes disciplined when the situation permits (Gottfredson, 2018). Consequently, this bond allows social control to be embodied in an individual to solidified the bonds towards social institutions.

Perhaps the most significant social institutions for juveniles are their family, peers and school. In terms on family, social control aspect, such as affective attachment between parents and children, commitment to conventional activities, family members' involvement in social activities, and encouraging children to accept the norms, are important for preventing delinquency (Gottfredson, 2018). Moreover, embodiment of parental control in the child, both parent's attachment to the child, and vice versa, are crucial in order to ensure the effectiveness of delinquency prevention (Koehn \& Kerns, 2018).

Farrington (2016) stated that human society is built on top of the family unit. Children that turn into delinquency often received little care and attention from their parents, living in constant conflicts, or lack supervision. In addition, Amani et al. (2018) mentioned that family engagement proves beneficial for young individuals during rehabilitation, specifically in juvenile crime cases. This signifies that the family unit plays a significant role towards delinquency behaviour. Therefore, in order to tackle delinquency, it is essential to understand the family of the juvenile, as well as the relationship between the juvenile and the family.

Families can be considered as one of the main socialising forces in a human's life. Family members are the role model of proper and improper conducts such as patience and respect towards each other for young children. However, children could learn unfavourable behaviours such as antisocial, aggressive, and demonstrate violent behaviour (Labella \& Masten, 2018). This statement alone proves that juvenile can end up becoming delinquent, if the teaching is done wrongly. Farrington (2016) proposed 
that positive parenting practices in early years could protect children from delinquency behaviour. In addition, such shield will o help adolescents to abstain themselves from delinquency.

As family members have close relationship with the children, their actions often have a significant impact to them. Therefore, social workers can help parents and the juvenile to identify and explore difficult and challenging family issues. Clinical social workers can provide individual, family, and group counselling to improve communication skills. Subsequently, this could help the relationships between parents and teens, resolving conflicts and tackling important mental health issues.

In order to deliver an effective intervention, competent social workers can deploy services related to family crisis intervention. These services utilise the educational approach to families. They are practical as an intervention and prevention during early stage of the crisis. As mentioned by Hawkins and Catalano (2017), it encourages proper communication between the both parents and children, and could act as a measure to suppress delinquent behaviours. In addition, it could prevent other siblings to become delinquent. Meanwhile, once the juvenile delinquents are not regulated under the jurisdiction of the juvenile court, the care of the children will be given back to their respective families. Therefore, family crisis intervention services, which is based on the systems-oriented and uses skill-training approach, aim to enhance supervision and communication skill among the parents, mend the broken relationship between parents and their children and subsequently prevent delinquency (Hawkins \& Catalano, 2017).

Social workers also train parents on delinquency prevention. This training includes effective family management and child rearing skills. Wikle and Hoagland (2019) asserted that family interactions, especially between mother and child, as the child grows and develops are important. Healthy attachment plays a crucial role in prevention and early intervention programs. In most cases, it is imperative for parents to have effective communication with their children. The attachment between the children and parents will become much stronger when both of them communicate with each other more in terms of thoughts, feelings, and values (Hirschi, 2017). Thus, social workers also provide parenting training, which principally focuses on communication skills between parents and children, such as basic interaction and effective listening to help the parents.

Social workers and parents could also conduct other activities, such as monitoring to supervise the juvenile's behaviour (Torres \& Mariscal, 2016). This ensures that the juvenile complies with the rules set and does not engage in criminal activities. The parents and the social worker could monitor the juvenile by direct or indirect monitoring. In direct monitoring, social worker and parents act as the "authority figure" who supervise the juvenile directly. Meanwhile, indirect monitoring involves indirect observation of the actions done by the juvenile. For instance, parents could ask for the location of the juveniles, or periodically call them or even ask someone else about their behaviour. The actions taken by the juveniles will be different based on how they are being monitored. Social workers will usually monitor and take note on the important "warning signs" of juveniles with declining behaviours.

Social workers can also provide the family with on-going developmentally appropriate opportunities to include the juvenile as a part of the family. Assigning children with appropriate roles in the family, the children will be able to contribute to the family functions. The child will be rewarded once he/she has performed the roles assigned excellently. This could create a stronger attachment to the family and reduce the possibility to perform delinquent behaviours. Hirschi (2017) claimed that the higher affection between children and parents could reduce a child's likelihood of engaging in delinquent behaviour.

Zastrow (2016) asserted that social workers must be able to practice on every levels, in addition to the complex nature of social problems. In this regard, the workers must consider all other social aspects because they require interventions as well as human beings depend on others in almost every aspect of their life. Thus, approval, feedback, friendship, recognition and support are highly sought and to understand human beings, it is natural to target group as the starting point. It is worth noting that 
group-based social work usually involves a vast area of direct social work practice (Garvin, Gutierrez \& Galinskey, 2017).

At the mezzo level, social workers can conduct a peer focus group intervention at the school level in order to address specific problem. Rather than using the traditional peer groups, which only involve leaders from student association or problematic students, social workers could devise a more promising model. This model combines the traditional model with a significant addition of leaders from student gangs and groups. In most cases, students and teachers choose those who are involved in the intervention while and the coordinator is tasked to do the final selection, it. For instance, student members of this peer leadership group spend an hour daily to discuss and identify problems in the school based on inputs from their fellow students. The input from the discussion sessions will be brought forward to the school administration and they will work together to create plausible and legitimate school policies to solve the problems. Moreover, the peer leadership group can become a source for the student's authoritative council to address general or disciplinary problems faced by the students in the school. Thus, peer leadership groups are better in overcoming problems compared to peer-oriented approaches, which only targets delinquent groups (Hawkins \& Weis, 2017).

The leaders of delinquency prone groups could gradually build connection with their other peers. Such connection could be developed between these two groups. Conceptually, this approach may increase attachment to the school. In addition, as the informal group leaders participate in peer leadership groups, it is foreseeable that it could lead more positive attitudes to school, due to the adjustment of school policies based on group members' responses. This could confine the delinquency prone groups (Fix, Alexander, \& Burkhart, 2018).

In the history of social work, the community-based social work is known as a part of social work ecosystems. This type of social work normally deals with a large social system and social change. Social work within a community encompasses a number of areas that involves community, mediation, policy, service and other systems intervention (Das, O'Neill, \& Pinkerton, 2016). The community itself covers a lot of areas for youth development at macro level. Whereas families, schools, and peers affect individual youths immediately, these socializing group are affected by the characteristics of community. These community areas could also influence the youths as they act as a ground where either delinquent or conforming behaviours occur. Gutierrez and Gant (2018) expressed that the practice of community work is a result of the analysis of social conditions. In addition, such practice forms relationships with various groups or to bring out changes in the community. Hence, social workers can implement community education model in community work. This model can be used to help communities gain more knowledge and understanding of juvenile delinquency, and simultaneously assisting the community in devising the prevention program. There are two (2) community-focused programme that seems favourable in preventing delinquency:

\section{a) Community Crime Prevention Programme}

This program utilises the neighbourhood watch and has been proven as effective in reducing burglaries in residential areas. While this approach is effective to deter crimes, what is more important is that the neighbourhood members utilise social networks for crime prevention (Hawkins \& Weis, 2017). Whenever the members of the group engage in these activities, they feel empowered with shared concern of the community. As a result, the community itself is able to come out with a set of regulations, which subsequently embodied in youths of the community. The youths will perceive criminal actions as risky and unacceptable.

\section{b) Community Youth Development Project}

Youths can participate in community support projects in order to prevent delinquency. Community members, regardless of their age, could be mobilised through assembled committees in developing delinquency-free environment. However, the objective seen as insurmountable due to lack of community youth participation of any leadership activities at school. If youths are given the 
opportunity to devise plans and organize activities that related to youth enhancement in the community, they will definitely feel at ease and motivated.

There is a number of projects that can be executed to support this initiative. Hawkins and Weis (2017) asserted that regardless of the activities, allowing these unexposed youths to participate in appropriate and legitimate establishments. Consequently, these youths will spend more time outside the school as they have commitments or attachments within the relevant channels.

To ensure the effectiveness of the intervention, social workers need to recognise the policies and laws related to juvenile delinquency at this level. Thus, social workers are required to assume multiple social work roles. The roles are including those of client advocate, broker of services, case manager, counsellor or therapist, group leader or facilitator, community organizer, administrator, supervisor, social planner, evaluator, educator, program developer, researcher, policy analyst, teacher and trainer (Coady \& Lehmann, 2016). They are deemed as individual changers or at times, systematic changers and often they are both depending on their practice setting and usual role. Moreover, they also have to take up several professional roles to advocate social justice and change and to improve social functioning.

In this light, when an underage juvenile comes in conflict with the law, social workers can assume the role as an advocate (Hoefer, 2019). The social worker will be able to deal with the police and the family of juvenile at the same time. Therefore, the first step that needs to be done by the social worker is to find out the offense made by the juvenile. Prior to that, they will need to equip themselves with knowledge of the related law. Meanwhile, they will inform the juvenile on his/her right including getting a legal representation, as well as to ensure that the juvenile's rights are not abused. Hence, social workers are responsible to protect the juvenile from torture, mixing with adult suspects and making sure that the juvenile are not remanded under police for a lengthy period of time. Therefore, social workers should be able to switch between roles as needed because there are various situations that require them to blend into the situation.

\section{Links between Micro, Mezzo and Macro Contexts}

Delinquency rates could be reduced indirectly through strengthening of the community institution or enhancing the attachment to the social organisation of the community. Despite conflicting results in several studies, families are somehow affected by the level of community engagement. While parents' supervision of children and healthy family relationship affect delinquency rate, the neighbourhood environment also plays an indirect role too. On the other hand, some studies suggest that the neighbourhood environment may in one way or another affect the relationship between family functioning and delinquency. In terms of location, the possibility of delinquency in poor urban neighbourhood is much higher compared to inner-city neighbourhoods (Mattson, 2016).

Social disorganization is indicated by the failure of a common value system at the community level. Once a community is disorganised, groups with their own rules and values will emerged (Sampson, 2017). A disorganised community may make the youths becoming more susceptible with deviant peer groups. On contrary, a more organised community will show a more pro-social environment to the youths. Chang \& Wu (2020) showed that the possibility of having conventional friends are influenced by the neighbourhood one lives in.

Finally, from the adolescent context, schools have to adjust their role based on the community itself. To illustrate, the number of school suspension (which correlates with delinquency) is linked to the background of the specific neighbourhood (Lane et al., 2017). Hirschi (2017) stated that suspension from school might cause the lack of engagement between the adolescent and the school. This finding is supported by Lane et al. (2017), which is in line with Hirschi's statement that shows that the bond to the school is somehow affected by the neighbourhood context. Furthermore, Hawkins and Weis (2017) found out that residents' participation and residential stability in a community might prevent 
delinquency from spreading across the community, which actually relates to the children's attachment to the school.

\section{Conclusion}

To prevent juvenile delinquency, a comprehensive developmental approach is needed based on the preventive, rehabilitative and development perspective of social work. It is then followed by the integration of different social theories and a combination of integrated social work intervention. Correspondingly, this approach may assist social workers to effectively design and select prevention strategies during initial stage of the problem.

Unhealthy behaviours, which originate from various factors, such as environment and past experiences, affect juvenile and lead to delinquency. Through the implementation of integrated social work, it might help social workers to understand the cause of the problems. In this case, social workers will be able to address this problem using the right techniques in order to restore the social functioning. Social workers also need to consider the theories related to delinquency. They need to practice various theories and approaches while helping the clients because clients are actually functioning on several dimensions. In this light, individuals and environment are linked to each other and any changes to one of them will definitely affect each other.

\section{References}

Agnew, R. (2019). The rise of Social Control Theory, Fall of Classic Strain Theory, and Reconciliation between Social Control and General Strain Theories. Fifty Years of Causes of Delinquency, Volume 25: The Criminology of Travis Hirschi, 29.

Aktipis, A., Cronk, L., Alcock, J., Ayers, J. D., Baciu, C., Balliet, D., ... \& Sullivan, D. (2018). Understanding cooperation through fitness interdependence. Nature Human Behaviour, 2(7), 429-431.

Alston, M., \& Bowles, W. (2019). Research for social workers: An introduction to methods. Routledge.

Amani, B., Milburn, N. G., Lopez, S., Young-Brinn, A., Castro, L., Lee, A., \& Bath, E. (2018). Families and the juvenile justice system: Considerations for family-based interventions. Family \& Community Health, 41(1), 55.

Barsky, A. E. (2019). Ethics and values in social work: An integrated approach for a comprehensive curriculum. Oxford University Press

Canda, E. R., Furman, L. D., \& Canda, H. J. (2019). Spiritual diversity in social work practice: The heart of helping. Oxford University Press, USA.

Chang, C. \& Wu, C. (2020). The friend influence in network neighbourhood context on adolescents' community attachment. International Journal of Adolescence and Youth, 25(1), 536-550.

Childress, S., Gioia, D., \& Campbell, J. C. (2018). Women's strategies for coping with the impacts of domestic violence in Kyrgyzstan: A grounded theory study. Social Work in Health Care, 57(3), 164-189.

Coady, N., \& Lehmann, P. (Eds.). (2016). Theoretical perspectives for direct social work practice: A generalist-eclectic approach. Springer Publishing Company.

Das, C., O’Neill, M., \& Pinkerton, J. (2016). Re-engaging with community work as a method of practice in social work: A view from Northern Ireland. Journal of Social Work, 16(2), 196-215.

Farrington, D. P. (2016). Juvenile delinquency prevention programs. Advancing Criminology and Criminal Justice Policy, 69.

Fix, R. L., Alexander, A. A., \& Burkhart, B. R. (2018). From family violence exposure to violent offending: examining effects of race and mental health in a moderated mediation model among confined male juveniles. International Journal of Offender Therapy and Comparative Criminology, 62(9), 2567-2585.

Gallant, J. P., \& Thyer, B. A. (2017). Usefulness of general systems theory in social work practice. In Human Behavior Theory and Social Work Practice (pp. 250-258). Routledge. 
Garvin, C. D., Gutierrez, L. M., \& Galinsky, M. J. (Eds.). (2017). Handbook of social work with groups. Guilford Publications.

Gehlert, S., \& Ward, T. S. (2019). Theories of health behavior. Handbook of health social work, 143163.

Gherardi, S. A., \& Whittlesey-Jerome, W. K. (2018). Role integration through the practice of social work with schools. Children \& Schools, 40(1), 35-44.

Gottfredson, M. R. (2018). General theory and global criminology: childhood environments, problem behaviors, and a focus on prevention. Asian Journal of Criminology, 13(4), 347-365.

Greene, R. R. (2017). Human behavior theory, person-in-environment, and social work method. In Human Behavior Theory and Social Work Practice (pp. 1-30). Routledge.

Gutierrez, L. M., \& Gant, L. M. (2018). Community practice in social work: Reflections on its first century and directions for the future. Social Service Review, 92(4), 617-646.

Hawkins, J. D., \& Catalano, R. F. (2017). Intensive family preservation services: Broadening the vision for prevention. In Reaching High-Risk Families (pp. 179-192). Routledge.

Hawkins, J. D., \& Weis, J. G. (2017). The social development model: An integrated approach to delinquency prevention. In Developmental and Life-Course Criminological Theories (pp. 3-27). Routledge.

Heyes, C. (2017). When does social learning become cultural learning?. Developmental Science, 20(2), e12350.

Heynen, E. J. E., Van der Helm, G. H. P., Wissink, I. B., Stams, G. J. J. M., \& Moonen, X. M. H. (2018). "I Don't Care About What You Want!" The relation between juvenile delinquents' responses to social problem situations and empathy in secure juvenile institutions. Journal of Interpersonal Violence, 33(9), 1412-1426.

Hirschi, T. (2017). A Control Theory of delinquency Travis Hirschi. In The Craft of Criminology. Routledge.

Hoefer, R. (2019). Advocacy practice for social justice. Oxford University Press.

Ife, J. (2019). New theories for social work practice: Ethical practice for working with individuals, families and communities. Jessica Kingsley Publishers.

Koehn, A. J., \& Kerns, K. A. (2018). Parent-child attachment: Meta-analysis of associations with parenting behaviors in middle childhood and adolescence. Attachment \& Human Development, 20(4), 378-405.

Labella, M. H., \& Masten, A. S. (2018). Family influences on the development of aggression and violence. Current Opinion in Psychology, 19, 11-16.

Lane, S. D., Rubinstein, R. A., Bergen-Cico, D., Jennings-Bey, T., Fish, L. S., Larsen, D. A., ... \& Robinson, J. A. (2017). Neighborhood trauma due to violence: a multilevel analysis. Journal of Health Care For The Poor And Underserved, 28(1), 446-462.

Larkin, S. (2018). A field guide for social workers: Applying your generalist training. SAGE Publications.

Levenson, J. (2017). Trauma-informed social work practice. Social Work, 62(2), 105-113.

Mattson, G. A. (2016). American hometown renewal: Policy tools and techniques for small town officials. Taylor \& Francis.

Ogundele, M. O. (2018). Behavioural and emotional disorders in childhood: A brief overview for paediatricians. World Journal of Clinical Pediatrics, 7(1), 9.

Sampson, R. J. (2017). Family management and child development: Insights from social disorganization theory. In Facts, frameworks, and forecasts (pp. 63-94). Routledge.

Sandu, A. E., \& Frunza, A. E. (2018). Ethical issues in social work practice. Information Science Reference/IGI Global.

Sullivan, C. J., \& Hirschfield, P. (2017). Problem behavior in the middle school years: An assessment of the social development model. In Developmental and Life-course Criminological Theories (pp. 173-200). Routledge.

Torres, G. C., \& Mariscal, V. V. (2016). Social workers perspectives of the protective and risk factors that affect youth in the juvenile justice system and child welfare system (Unpublished Doctoral Dissertation or Master's Thesis). California State University, San Bernardino.

Von Stumm, S. (2017). Socioeconomic status amplifies the achievement gap throughout compulsory education independent of intelligence. Intelligence, 60, 57-62. 
DOI: https://doi.org/10.47405/aswj.v5i2.139

Wikle, J. S., \& Hoagland, A. (2019). Adolescent interactions with family and emotions during interactions: Variation by family structure. Journal of Family Psychology. Advance online publication. No Pagination Specified.

Zastrow, C. (2016). Empowerment series: Introduction to social work and social welfare:

Empowering people. Cengage Learning. 